Supplementary Information for

\title{
Propagating uplift controls on high-elevation, low-relief landscape formation in Southeast Tibetan Plateau
}

\author{
X. P. Yuan ${ }^{1,2}$, K. L. Huppert ${ }^{2}$, J. Braun ${ }^{2}$, X. Shen ${ }^{2,3}$, J. Liu-Zeng ${ }^{4}$, L. Guerit ${ }^{5}$, \\ S. G. Wolf ${ }^{6}$, J. F. Zhang ${ }^{1}$, M. Jolivet ${ }^{5}$ \\ ${ }^{1}$ School of Earth Sciences, China University of Geosciences, 430074 Wuhan, China \\ ${ }^{2}$ Helmholtz Centre Potsdam, German Research Centre for Geosciences, 14473 Potsdam, Germany \\ ${ }^{3}$ National Institute of Natural Hazards, Ministry of Emergency Management of China, 10085 Beijing, \\ China \\ ${ }^{4}$ Institute of Surface Earth System Science, Tianjin University, 300072 Tianjin, China \\ ${ }^{5}$ University of Rennes, CNRS, Géosciences Rennes, UMR 6118, 35000 Rennes, France \\ ${ }^{6}$ Department of Earth Science, University of Bergen, N-5020 Bergen, Norway
}

\section{Contents of the GSA Data Repository}

Text DR1-DR2

Figures DR1- DR9

Captions for Movies DR1-DR4

\section{Text DR1. METHODS}

\section{Text DR1.1 Landscape evolution model}

We use the FastScape landscape evolution model (Yuan et al., 2019) to solve equations governing long-term fluvial erosion and sediment transport:

$$
\frac{\partial h}{\partial t}=U-K_{f} \tilde{p}^{m} A^{m} S^{n}+\frac{G}{\tilde{p} A} \int_{A}\left(U-\frac{\partial h}{\partial t}\right) d A,
$$

and diffusive hillslope evolution (Culling, 1960): 


$$
\frac{\partial h}{\partial t}=K_{D} \nabla^{2} h
$$

where $\partial h / \partial t$ is the rate of change of topography (m/yr), $U$ is the uplift rate $(\mathrm{m} / \mathrm{yr}), K_{f}$ is the bedrock erodibility $\left(\mathrm{m}^{1-2 m} / \mathrm{yr}\right), \tilde{p}$ is the variation in precipitation relative to the mean precipitation rate, $A$ is the drainage area $\left(\mathrm{m}^{2}\right), S$ is the slope in the steepest-descent drainage direction, $m$ and $n$ are the stream power model exponents (Howard and Kerby, 1983; Whipple and Tucker, 1999), $G$ is a dimensionless deposition coefficient that has a value close to unity (Guerit et al., 2019), and $K_{D}$ is the hillslope diffusion coefficient $\left(\mathrm{m}^{2} / \mathrm{yr}\right)$. We use a $n=1$ and $m$ $=0.4$, following previous studies and based on the concavity $m / n \sim 0.4$ that minimizes scatter between the observed $\chi$-elevation profiles of tributary profiles in the three basins (Fig. DR2).

This model accounts for mixed bedrock-alluvial channel dynamics (Davy and Lague, 2009) and hillslope diffusion, and it has the ability to reproduce a wide spectrum of observed river profile and planview morphologies (Yuan et al., 2019). We assume a uniform bedrock erodibility $K_{f}\left(\mathrm{~m}^{0.2} / \mathrm{yr}\right)$ to simplify the simulation and test a range of erodibilities to find the value best matching the observed river profile morphology (Fig. DR4). Deposition coefficients are also tested to explore the behaviors of modeling results (Fig. DR5). We assume a constant value for the diffusion coefficient $K_{D}$ of $0.01 \mathrm{~m}^{2} / \mathrm{yr}$ (Densmore et al., 2007). The other values of $K_{D}=0,0.001$, and $0.1 \mathrm{~m}^{2} / \mathrm{yr}$ are tested, which show approximately the same modeling results.

\section{Text DR1.2 Model setup}

We define an initial rectangular domain size of $1300 \times 500 \mathrm{~km}$ (Fig. 2A), with each cell size of $2 \times 2 \mathrm{~km}$, for the model run of $50 \mathrm{Myr}$ and a time step length of 1000 years. We have tested other spatial resolutions (e.g., $4 \times 4 \mathrm{~km}$ and $5 \times 5 \mathrm{~km}$ ), which do not influence our modeling results in this work. Paleotopography from the central plateau to the SE margin before uplift is poorly 
constrained (Mulch and Chamberlain, 2006; Spicer et al., 2020). Many studies suggest that the headwaters of the Three Rivers initiated from a low-elevation basin bounded by the Gangdese and Qiangtang mountains at $~ 50 \mathrm{Ma}$ (Ding et al., 2014; Su et al., 2019), with the basin hosting large lake systems in the middle Paleogene (Spicer et al., 2020). To mimic initial low-elevation basins and horizontal indentation of the Indian plate into Asia (Replumaz and Tapponnier, 2003), we simply assume an initial elevation $h_{i}$ seeded with random $\leq 100-\mathrm{m}$ amplitude white noise in our numerical simulation (Fig. 2A and Movie DR1). The southeast boundary of the model domain is an open boundary through which water and sediment can outflow. We impose a no-flux leaving boundary condition on the other three boundaries.

The model is subjected to a uniform horizontal shortening rate in NW-SE ( $x$-direction; parallel to the propagating direction, Fig. 2A), and a non-uniform shortening rate in the SW-NE ( $y$ direction) representing the indentation of the Indian plate into Asia. In the NW-SE, the current Global Positioning System (GPS) data in the headwater and the lower reach are $\sim 20 \mathrm{~mm} / \mathrm{yr}$ and 15-16 mm/yr, respectively (Liang et al., 2013). The difference in horizontal rates ( $4 \mathrm{~mm} / \mathrm{yr}$ ) on the two boundaries represents the shortening rate of our model domain. The total shortening in our model is thus set to $200 \mathrm{~km}$ for the model run of $50 \mathrm{Myr}$, i.e., $V_{x}=4 \mathrm{~mm} / \mathrm{yr}$ (Fig. $2 \mathrm{~A}$ ). We use present-day GPS data because long-term shortening rates are not available in this region. In the SW-NE, the maximum indentation distance relative to the boundary is $\sim 200 \mathrm{~km}$ (Fig. DR3). We impose a sinuous horizontal strain rate in this direction to model the non-uniform rate with a maximum rate of $V_{y}=200 \mathrm{~km} / 50 \mathrm{Myr}=4 \mathrm{~mm} / \mathrm{yr}$.

\section{Text DR1.3 Propagating uplift}

Elevations $h_{f}$ of the SE Tibetan Plateau at distances $x$ southeast of the plateau margin, $x_{0}$, are well described by a logistic function as 


$$
h_{f}=\frac{h_{0}}{1+e^{\left(x-x_{0}\right) / W}},
$$

where $h_{0}$ is the maximum, steady-state elevation of the plateau and $W$ is the characteristic width of propagating uplift. Assume the plateau margin propagating southeast in time $t$ at velocity $v_{0}$, the propagating distance $x_{0}$ is

$$
x_{0}=v_{0} t
$$

The present propagating margin can be approximated from high $k_{s n}$ (a proxy for uplift rate) section, which is $\sim 950+200$ (the NW-SE shortening length) $=1150 \mathrm{~km}$ from the initial, left model boundary (see Fig. DR3). The propagating velocity in our model simulation is thus $v_{0}=$ $1150 \mathrm{~km} / 50 \mathrm{Myr}=23 \mathrm{~mm} / \mathrm{yr}$. We set the maximum elevation of $h_{0}=6 \mathrm{~km}$, corresponding to the maximum elevation observed in the Tibetan Plateau. Based on the swath profiles across the SE plateau margin (Royden et al., 2008; Clark and Royden, 2000; Whipple et al., 2017) and Equation DR3, we determine the characteristic width of propagating uplift to be $W=150 \mathrm{~km}$. The uplift rate $U$ can be calculated from the derivative of the topographic profile in Equation DR3, assuming the morphology of this profile is predominately set by tectonic uplift, rather than erosional processes:

$$
U=\frac{\partial h_{f}}{\partial t}=\frac{h_{0} v_{0} e^{\left(x-x_{0}\right) / W}}{W\left[1+e^{\left(x-x_{0}\right) / W}\right]^{2}}
$$

The above uplift pattern is shown in Fig. 2A alongside the model $x$-axis with high uplift rates at the propagating margin and low rates in the upper and lower reaches. Uplift rates are initially zero across the model domain, increase to the maximum velocity of $U\left(x=x_{0}\right)=h_{0} v_{0} /(4 W)$ $=6 \mathrm{~km} \times 23 \mathrm{~mm} / \mathrm{yr} /(4 \times 150 \mathrm{~km})=0.23 \mathrm{~mm} / \mathrm{yr}$ with passage of the propagating uplift wave, then reduce to lower values when the topography is close to the maximum plateau elevations of $h_{0}$ $=6 \mathrm{~km}$. 


\section{Text DR2. RIVER PROFILE MORPHOLOGY OF THE SE TIBETAN PLATEAU}

We use plots of elevation versus an upstream integral of drainage area, $\chi$ (Perron and Royden, 2013), to quantitatively compare modeled and observed river profiles. By accounting for the inverse scaling between drainage area and slope, $\chi$ provides a horizontal coordinate transformation that linearizes steady-state river profiles such that their steepness can be readily compared across scales. Based on Equation 1, the slope of a river at steady state is

$$
S=\frac{d h}{d x}=k_{s n} A^{-m / n}
$$

Integrating this equation along the river profile from the base level $x_{b}$ to a point $x$, we have

$$
h(x)=h\left(x_{b}\right)+k_{s n} A_{0}^{-m / n} \chi(x) \text {, with } \chi(x)=\int_{x_{b}}^{x}\left(\frac{A_{0}}{A(x)}\right)^{m / n} d x
$$

where $A_{0}\left(=1 \mathrm{~m}^{2}\right)$ is a reference drainage area. The change in channel elevation with respect to $\chi$ is $k_{s n}$.

We choose the drainage basins similar to the study area of the Three Rivers region in Whipple et al. (2017). The drainage basin outlets are at the SE Tibetan Plateau margin. Farther southeast along the SE plateau margin (Schoenbohm et al., 2006) covers a much larger area because the Three Rivers are widely separated and experienced major reorganization (e.g., Zheng et al., 2013). This part has more complex geology which requires further studies. We use TopoToolbox2 (Schwanghart and Scherler, 2013) to extract the drainage network of the Three Rivers from the Shuttle Radar Topography Mission (SRTM) digital elevation model (30-m horizontal resolution). We then calculate $\chi$ along the largest tributaries of the Three Rivers for various concavities and plot $\chi$ versus elevation profiles ( $\chi$-elevation plots; Fig. DR2).

The concavity $m / n=0.4$ minimizes scatter between the $\chi$-elevation plots of different tributaries. If spatial precipitation rate $p(x)$ is considered, Equation DR7 becomes $\chi(x)=$ $\int_{x_{b}}^{x}\left(\frac{p_{0} A_{0}}{p(x) A(x)}\right)^{m / n} d x$, with $p_{0}$ an arbitrary scaling factor for the precipitation rate (Yang et al., 
2015). Modern upstream-averaged mean annual precipitation (Figs. 1D-F and DR1) varies by $<1 \mathrm{~m}$ within the study catchments and does not appear to explain the observed changes in channel steepness along the river profiles (Yang et al., 2015). For example, in the Salween River (Fig. DR1), some lower $k_{s n}$ segments correspond to higher precipitation rates. In addition, no quantitative studies show how Asian climate evolved in this region since 50 Ma because the growth pattern of the plateau affects the Asian climate (e.g., Botsyun et al., 2019). Thus, for simplicity, we assume a constant precipitation rate for the landscape evolution modeling in this work.

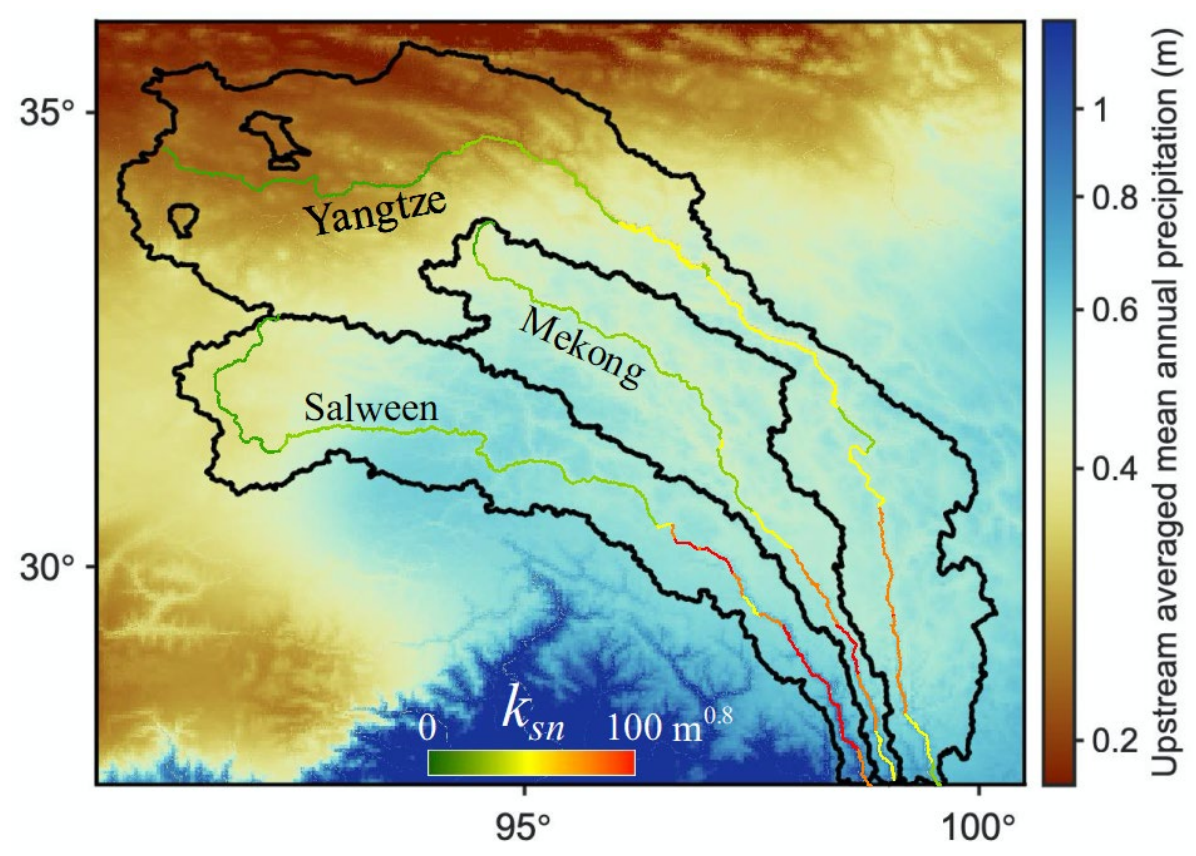

Figure DR1. Present-day upstream-averaged mean annual precipitation (for the period 19702000) over the Three Rivers region from the WorldClim 2.5 minute-resolution dataset (Fick and Hijmans, 2017). 

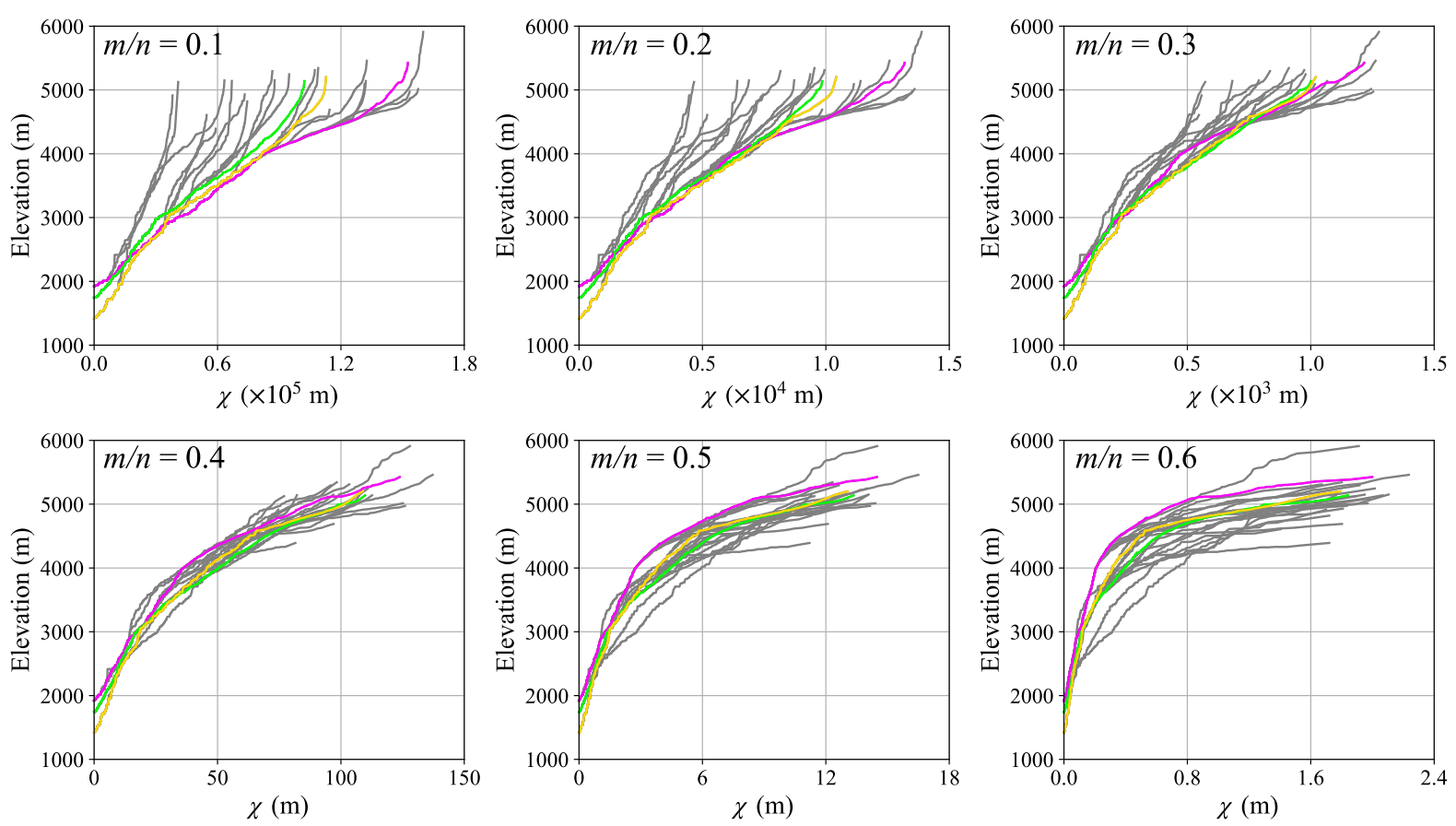

Figure DR2. $\chi$-elevation plots for all rivers with drainage area exceeding $5 \mathbf{~ k m}^{2}$ in the Three Rivers

region. The colored $\chi$-elevation curves correspond to the three mainstem rivers (yellow: Salween; green: Mekong; magenta: Yangtze). A concavity of $m / n=0.4$ collapses the mainstem and tributary profiles onto a consistent $\chi$-elevation curve. 


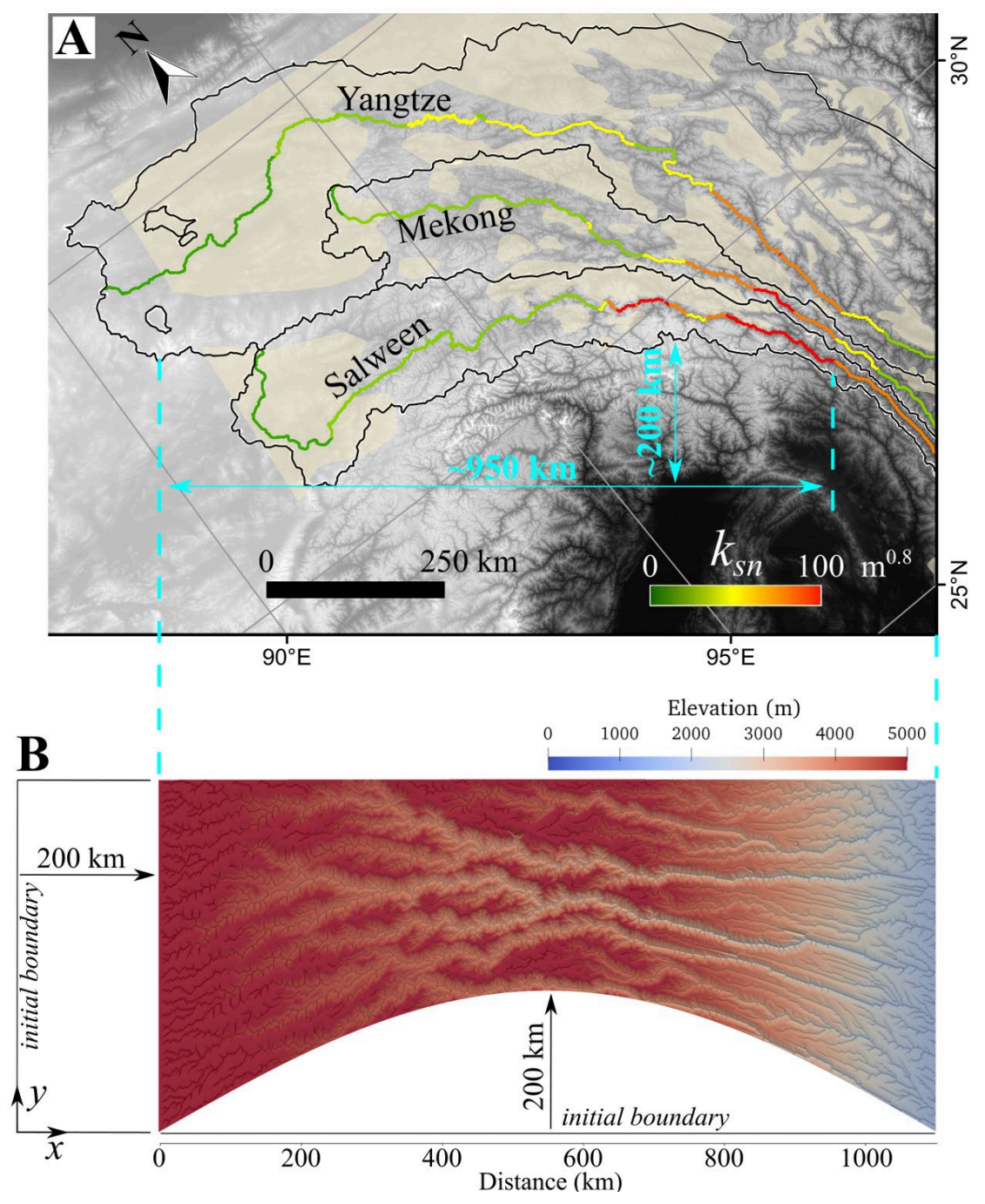

Figure DR3. Spatial constraints on horizontal deformation and propagating uplift from the observed topography in the Three Rivers region (A) and their implementation in the model domain (B). We use high $k_{s n}\left(\mathrm{~m}^{0.8}\right.$; a proxy for uplift rate) to identify the present-day location of the propagating margin, $\sim 950 \mathrm{~km}$ from the northwestern boundary of the drainage basins. Thus, the presentday propagating margin is $\sim 950+200$ (the NW-SE shortening length) $=1150 \mathrm{~km}$ from the initial, left model boundary in B. In the SW-NE, the maximum indentation of the Indian plate into Asia relative to the lower boundary is $\sim 200 \mathrm{~km}$ in $\mathbf{A}$. 


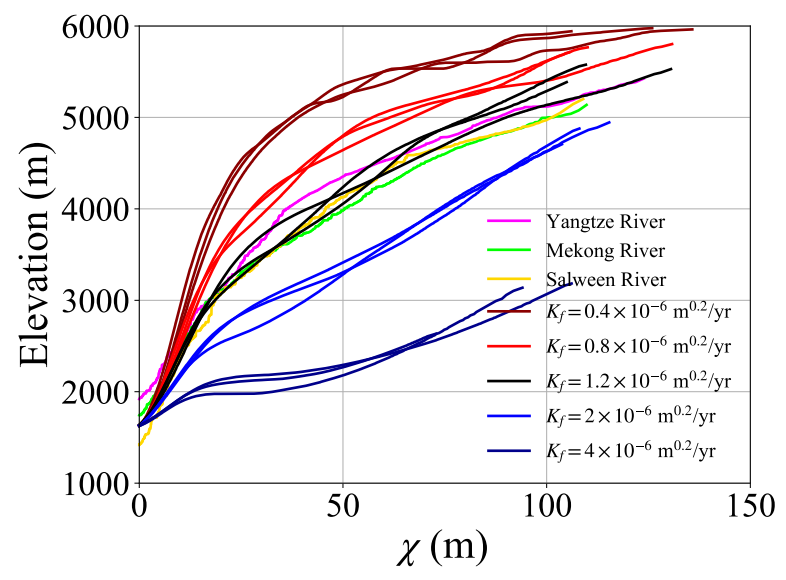

Figure DR4. Comparisons of modeled and observed $\chi$-elevation plot of the mainstem rivers for the propagating uplift model. Colored curves show the $\chi$-elevation plots for different erodibilities $K_{f}$ $=0.4 \times 10^{-6} \mathrm{~m}^{0.2} / \mathrm{yr}, 0.8 \times 10^{-6} \mathrm{~m}^{0.2} / \mathrm{yr}, 1.2 \times 10^{-6} \mathrm{~m}^{0.2} / \mathrm{yr}, 2 \times 10^{-6} \mathrm{~m}^{0.2} / \mathrm{yr}$, and $4 \times 10^{-6} \mathrm{~m}^{0.2} / \mathrm{yr}$, using the deposition coefficient $G=1$ (Guerit et al., 2019).
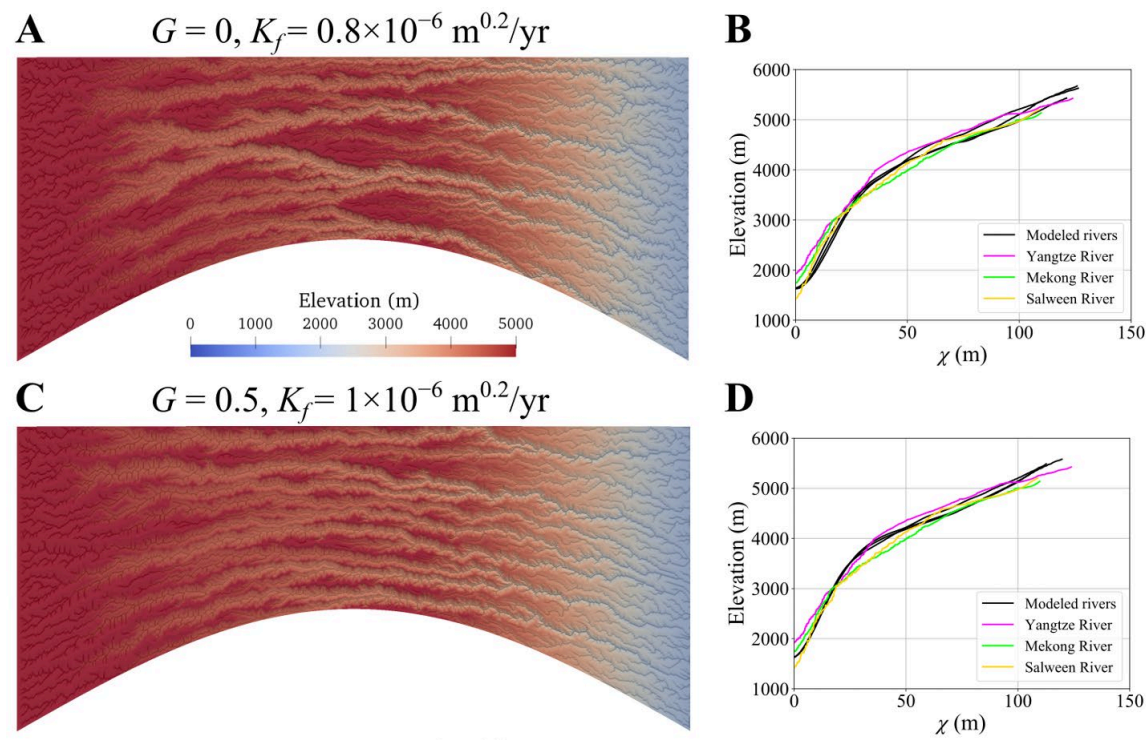

E $\quad G=1, K_{f}=1.2 \times 10^{-6} \mathrm{~m}^{0.2} / \mathrm{yr}$

$\mathbf{F}$
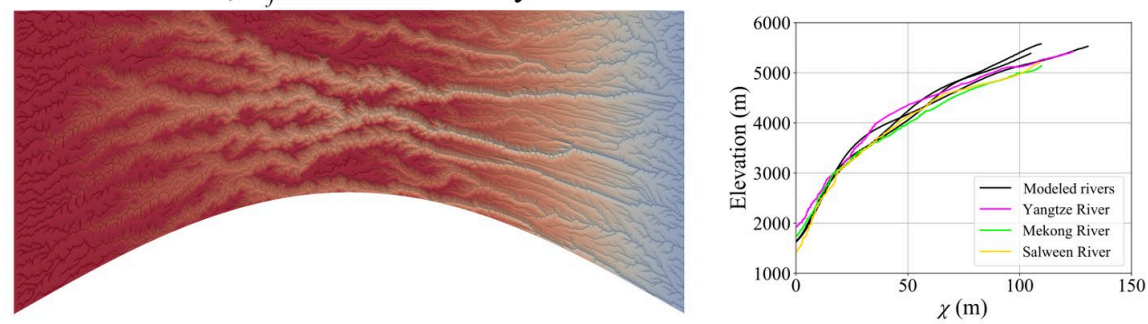

Figure DR5. Modeled landscape and the corresponding $\chi$-elevation plots for various of deposition coefficients $\boldsymbol{G}$. The modeled landscape (A) and the $\chi$-elevation plot (B) for the detachment-limited river incision $(G=0$ in Equation DR1). The modeled landscape (C) and the $\chi$-elevation plot (D) for the 
sediment-flux dependent river incision $(G=0.5)$. The modeled landscape $(\mathbf{E})$ and the $\chi$-elevation plot (F) for the reference case $(G=1)$. The erodibility chosen for each case is based on the correspondence between observed and modeled river profiles, e.g., see the example in Fig. DR4. The cases of $\mathbf{A}$ and $\mathbf{C}$ show approximately the same modeling results as the reference case of $\mathbf{E}$, including elongated drainage basins, low-relief surfaces and deep valleys, and a similar fit between observed and modeled river profiles. Regardless of the specific erosion and deposition parameters used, the propagating uplift pattern controls the first-order erosional dynamic of landscape evolution and the formation of the lowrelief surfaces.
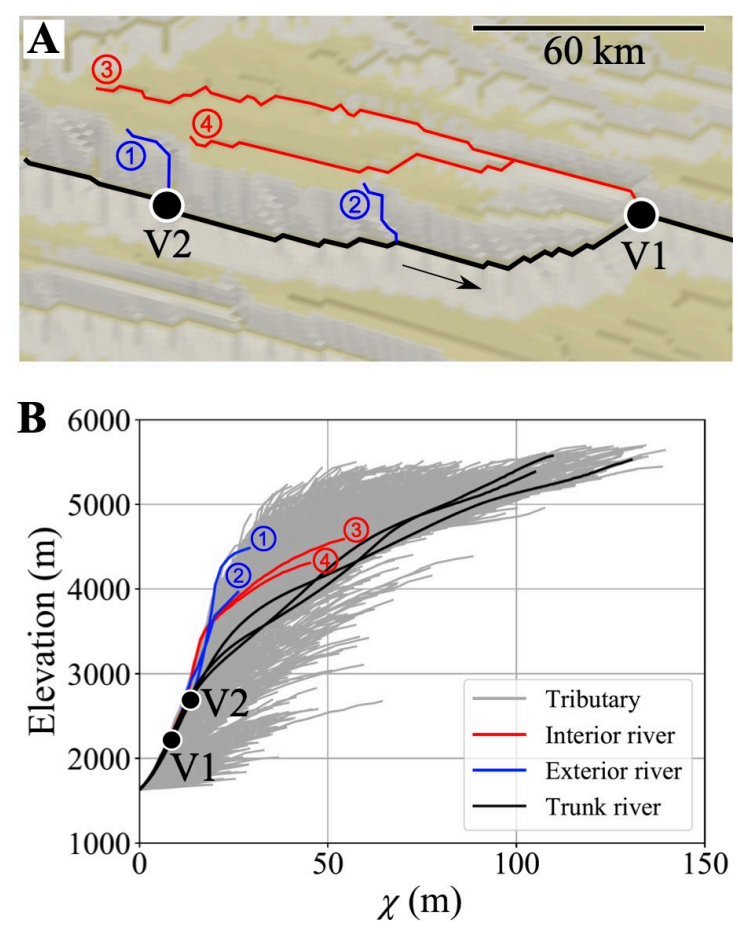

Figure DR6. River courses and $\chi$-elevation plots for a low-relief surface (see Fig. 2C for location).

A, The low-relief surfaces (yellow shaded) and the representative four courses. B, $\chi$-elevation plots for rivers shown in A and tributaries (grey curves). Red and blue courses are interior rivers on the low-relief landscape and exterior rivers, respectively. $\chi$-elevation plots of the modeled interior and exterior rivers are similar to the observed ones, see Extended Data Fig. 2 in Yang et al. (2015). 


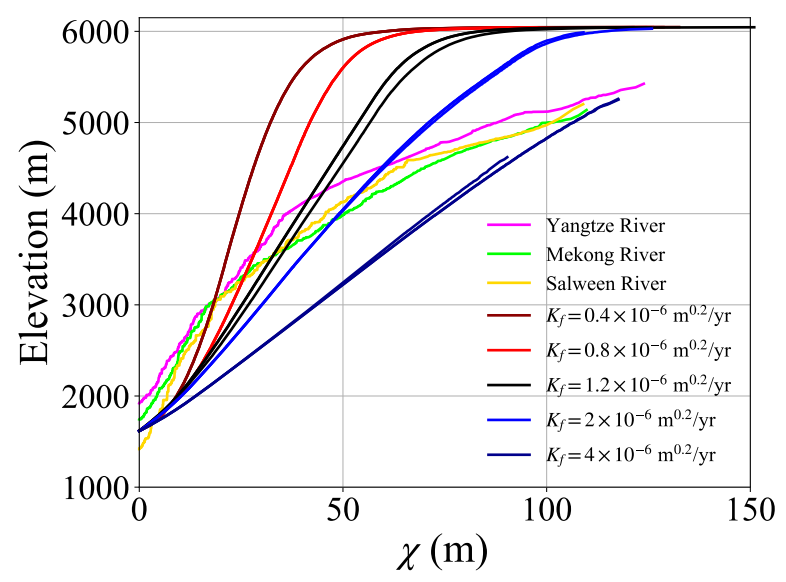

Figure DR7. Comparisons of modeled and observed $\chi$-elevation plot of the mainstem rivers for the uniform uplift model. Colored curves show the $\chi$-elevation plots for different erodibilities $K_{f}=$ $0.4 \times 10^{-6} \mathrm{~m}^{0.2} / \mathrm{yr}, 0.8 \times 10^{-6} \mathrm{~m}^{0.2} / \mathrm{yr}, 1.2 \times 10^{-6} \mathrm{~m}^{0.2} / \mathrm{yr}, 2 \times 10^{-6} \mathrm{~m}^{0.2} / \mathrm{yr}$, and $4 \times 10^{-6} \mathrm{~m}^{0.2} / \mathrm{yr}$.
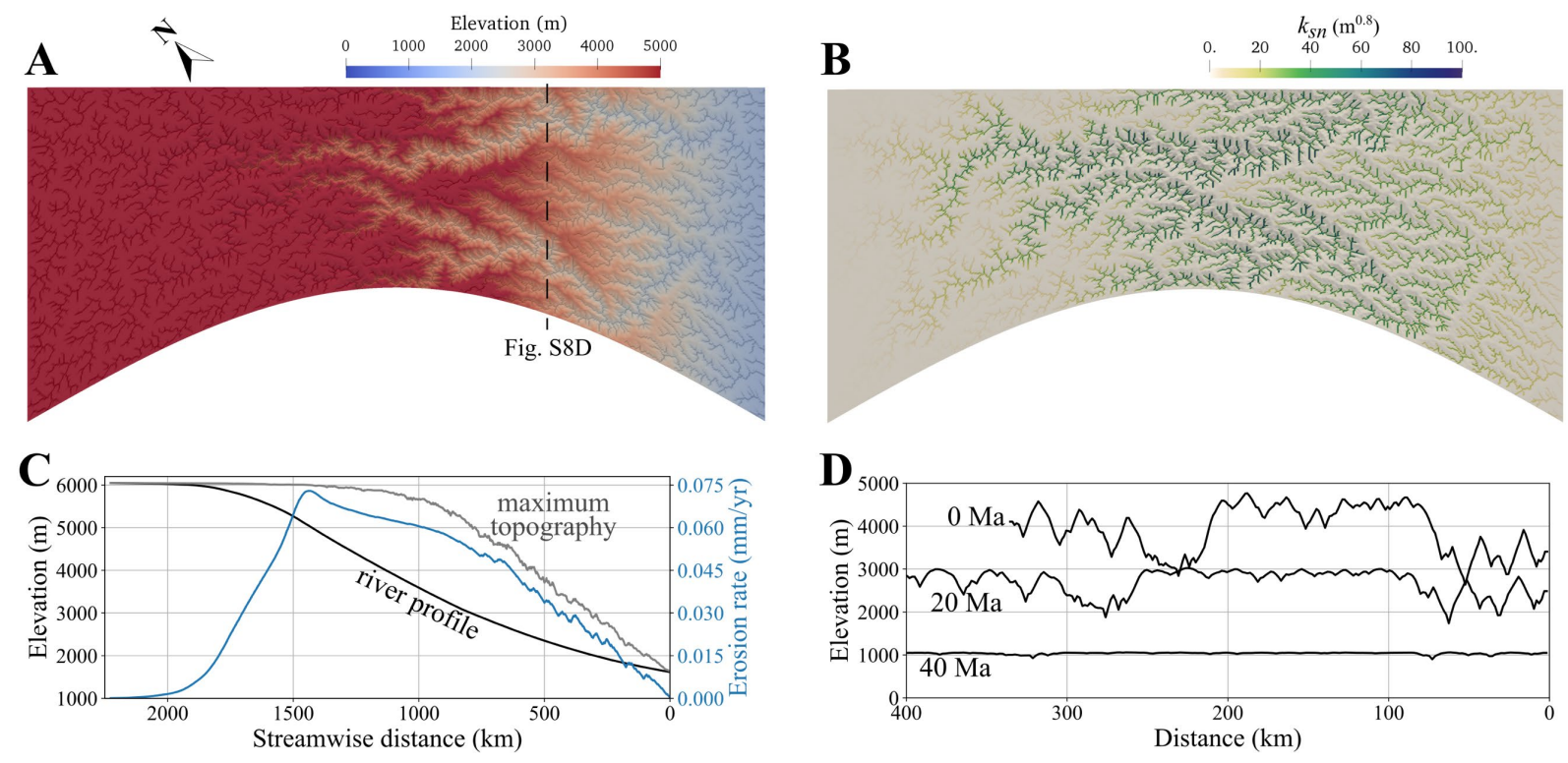

Figure DR8. Numerical model of landscape evolution of the SE Tibetan Plateau in response to a

uniform uplift rate. A-B, Modeled elevation, and normalized channel steepness $k_{s n}$ (Movie DR4) on the landscape at $0 \mathrm{Ma}$. $\mathbf{C}$, Modeled river profile, maximum topography, and erosion rate along the river profile. D, Topography at $40 \mathrm{Ma}, 20 \mathrm{Ma}$, and $0 \mathrm{Ma}$ located at the dashed lines in A. We model this scenario of uniform uplift to reach the same final elevation in Equation DR3 using the same erodibility $\left(K_{f}=1.2 \times 10^{-6} \mathrm{~m}^{0.2} / \mathrm{yr}\right)$ of the scenario of propagating uplift. Under uniform uplift, low-relief interfluves are eventually dissected by a wave of upstream-propagating river incision. They then erode at the same 
rate (the rock uplift rate) as the mainstem rivers (panel $\mathbf{C}$ ), inconsistent with the ten-fold difference in erosion rates measured in mainstem river valleys and their tributaries.
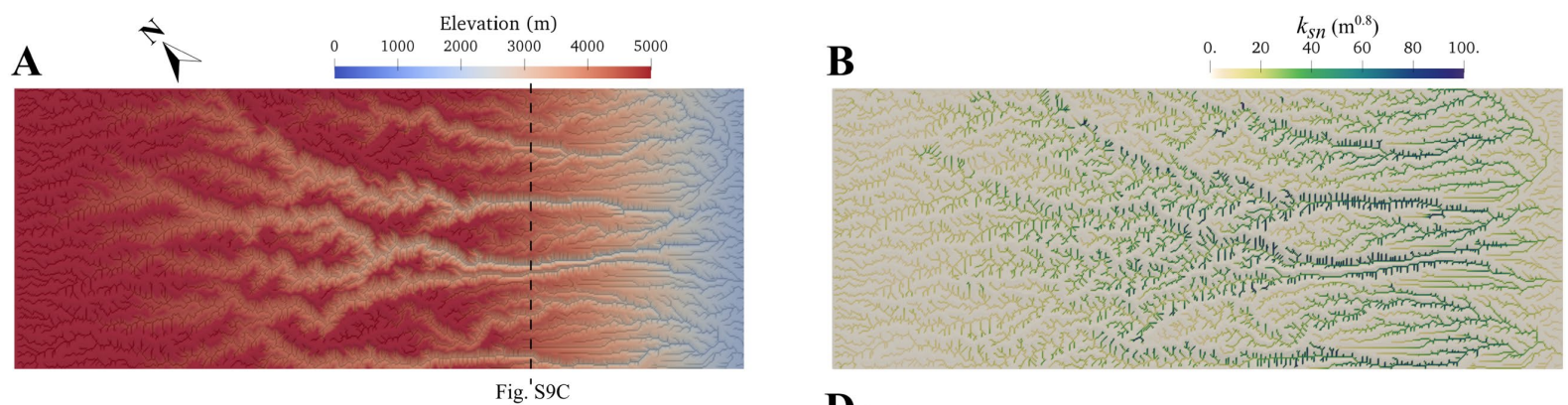

C
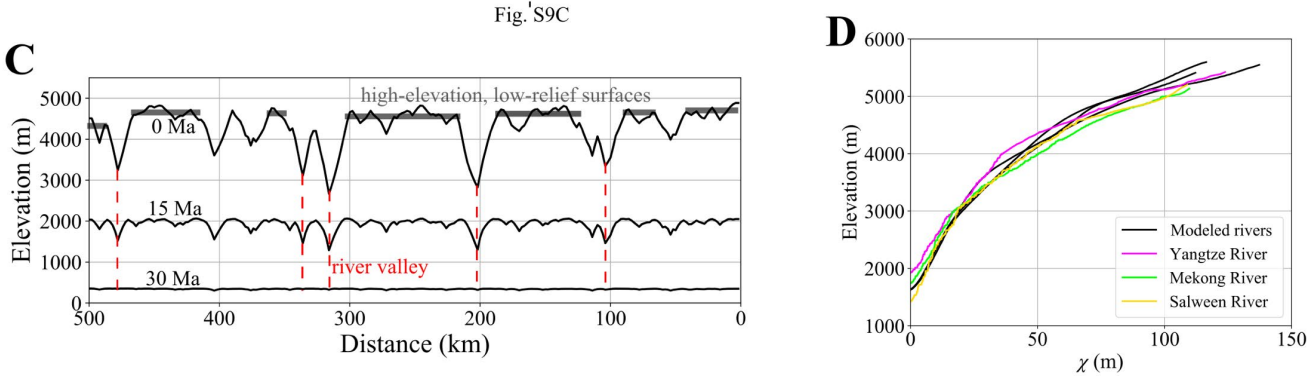

Figure DR9. Numerical model of landscape evolution of the SE Tibetan Plateau in response to propagating uplift without horizontal shortening. A-B, Modeled elevation, and steepness index $k_{s n}$ on the landscape at $0 \mathrm{Ma}$. C, Topography at $30 \mathrm{Ma}, 15 \mathrm{Ma}$, and $0 \mathrm{Ma}$ located at the dashed lines in $\mathbf{A}$, showing the pattern of incision into a regional low-relief surface. D, Comparison of modeled and observed $\chi$-elevation plot for the mainstem rivers. 
Movie DR1. Landscape evolution of the model in response to propagating uplift and horizontal shortening for model run of $50 \mathrm{Myr}$.

Movie DR2. Evolution of channel steepness $k_{s n}\left(\mathrm{~m}^{0.8}\right)$ on the landscape in response to propagating uplift and horizontal shortening for model run of $50 \mathrm{Myr}$.

Movie DR3. Evolution of $\chi$ values and high-elevation, low-relief surfaces on the landscape in response to propagating uplift and horizontal shortening for model run of $50 \mathrm{Myr}$.

Movie DR4. Evolution of channel steepness $k_{s n}\left(\mathrm{~m}^{0.8}\right)$ on the landscape in response to a uniform uplift rate for model run of $50 \mathrm{Myr}$. 


\section{References}

Botsyun, S., Sepulchre, P., Donnadieu, Y., Risi, C., Licht, A. and Rugenstein, J.K.C., 2019. Revised paleoaltimetry data show low Tibetan Plateau elevation during the Eocene. Science, 363(6430).

Culling, W. E. H., 1960. Analytical theory of erosion. The Journal of Geology, 68(3), 336-344.

Davy, P. and Lague, D., 2009. Fluvial erosion/transport equation of landscape evolution models revisited. Journal of Geophysical Research: Earth Surface, 114(F3).

Densmore, A.L., Allen, P.A., Simpson, G., 2007. Development and response of a coupled catchment fan system under changing tectonic and climatic forcing. Journal of Geophysical Research: Earth Surface, 112(F01002), doi:10.1029/2006JF000474.

Ding, L., Xu, Q., Yue, Y., Wang, H., Cai, F. and Li, S., 2014. The Andean-type Gangdese Mountains: Paleoelevation record from the Paleocene-Eocene Linzhou Basin. Earth and Planetary Science Letters, 392, 250-264.

Fick, S.E. and Hijmans, R.J., 2017. WorldClim 2: new 1-km spatial resolution climate surfaces for global land areas. International journal of climatology, 37(12), 4302-4315.

Guerit, L., Yuan, X.P., Carretier, S., Bonnet, S., Rohais, S., Braun, J., Rouby, D., 2019. Fluvial landscape evolution controlled by the sediment deposition coefficient: Estimation from experimental and natural landscapes. Geology, 47(9), 853-856.

Howard, A.D., Kerby, G., 1983. Channel changes in badlands. Geological Society of America Bulletin, 94(6), 739-752.

Liang, S., Gan, W., Shen, C., Xiao, G., Liu, J., Chen, W., Ding, X. and Zhou, D., 2013. Three-dimensional velocity field of present-day crustal motion of the Tibetan Plateau derived from GPS measurements. Journal of Geophysical Research: Solid Earth, 118(10), 5722-5732.

Mulch, A. and Chamberlain, C.P., 2006. The rise and growth of Tibet. Nature, 439(7077), 670-671.

Replumaz, A., Tapponnier, P., 2003. Reconstruction of the deformed collision zone between India and Asia by backward motion of lithospheric blocks. Journal of Geophysical Research: Solid Earth, 108(B6), doi:10.1029/2001JB000661.

Royden, L.H., Burchfiel, B.C. and van der Hilst, R.D., 2008. The geological evolution of the Tibetan Plateau. Science, 321(5892), 1054-1058.

Schwanghart, W., Scherler, D., 2013. TopoToolbox 2-an efficient and user-friendly tool for Earth surface sciences. Earth Surface Dynamics Discussions, 1, 261-275.

Spicer, R.A., Su, T., Valdes, P.J., Farnsworth, A., Wu, F.X., Shi, G., Spicer, T.E. and Zhou, Z., 2020. Why the 'Uplift of the Tibetan Plateau' is a myth. National Science Review, doi: 10.1093/nsr/nwaa091.

Su, T., Farnsworth, A., Spicer, R.A., Huang, J., Wu, F.X., Liu, J., Li, S.F., Xing, Y.W., Huang, Y.J., Deng, W.Y.D. and Tang, H., 2019. No high Tibetan Plateau until the Neogene. Science advances, 5(3), p.eaav2189.

Whipple, K.X. and Tucker, G.E., 1999. Dynamics of the stream-power river incision model: Implications for height limits of mountain ranges, landscape response timescales, and research needs. Journal of Geophysical Research: Solid Earth, 104(B8), $17661-17674$.

Zheng, H., Clift, P.D., Wang, P., Tada, R., Jia, J., He, M. and Jourdan, F., 2013. Pre-miocene birth of the Yangtze River. Proceedings of the National Academy of Sciences, 110(19), 7556-7561. 